\title{
In Situ Observation of Bainite Transformation and Simultaneous Carbon Enrichment in Austenite in Low-Alloyed TRIP Steel Using Time-of-Flight Neutron Diffraction Techniques
}

\author{
YUSUKE ONUKI, TAKASHI HIRANO, AKINORI HOSHIKAWA, SHIGEO SATO, \\ and TOSHIRO TOMIDA
}

\begin{abstract}
An in situ neutron diffraction experiment during austempering of low-alloyed transformationinduced plasticity steel, Fe-1.48Si-1.52Mn- $0.15 \mathrm{C}$, in wt pet was conducted. In this study, timeof-flight neutron diffractometer with a large detector coverage, iMATERIA at J-PARC MLF, was employed. The phase fraction and carbon concentration in austenite could be quantitatively determined with a time resolution 1 minute although considerable textures existed for both ferrite and austenite. The carbon concentration in austenite during austempering was found to be inhomogeneous, resulting in a bimodal concentration distribution. The low-carbon region was consumed by bainite transformation whereas the high-carbon austenite slightly increased and even survived the final cooling to room temperature, forming a retained austenite. The rate of bainite transformation was affected by the state prior to the start of austempering. Consequently, different morphological features of the retained austenite were formed. More block-shaped austenite was observed in the case of slower bainite transformation, and it was determined that film-shaped austenite could also exist. The average carbon concentration was similar to that of high-carbon austenite during austempering. Hence, the film and block shapes of the retained austenite do not necessarily reflect the difference in carbon concentration.
\end{abstract}

https://doi.org/10.1007/s11661-019-05415-6

(C) The Minerals, Metals \& Materials Society and ASM International 2019

\section{INTRODUCTION}

HEAT treatment is one of the most fundamental processes in the manufacturing of metallic materials. ${ }^{[-3]}$ In particular, in steel industries, the researchers are focusing on austempering, which involves isothermal heating at approximately $673 \mathrm{~K}$ after cooling from a higher temperature. This process develops complex microstructures, including bainite and retained austenite, leading to the production of transformation-induced plasticity (TRIP) steels. ${ }^{[4]}$ Hence, several in situ diffraction studies have focused on the behavior of austenite and the development of the bainite structure during austempering. ${ }^{[5-8]}$ In general, a diffraction experiment

YUSUKE ONUKI and AKINORI HOSHIKAWA are with the Frontier Research Center for Applied Atomic Sciences, Ibaraki University, Tokai 319-1106, Japan. Contact e-mail: yusuke.onuki.0@vc.ibaraki.ac.jp TAKASHI HIRANO and SHIGEO SATO are with the Graduate School of Science and Engineering, Ibaraki University, Hitachi 316-8511, Japan. TOSHIRO TOMIDA is with the Planning Division, Ibaraki Prefectural Government, Tokai 319-1106, Japan.

Manuscript submitted December 19, 2018.

Article published online August 22, 2019 can provide the phase fractions and lattice parameter. The latter for austenite is particularly important, because it is the function of carbon concentration. The carbon enrichment in austenite is one of the most important controlling mechanisms of bainite transformation. ${ }^{[1]}$ In addition, it affects the deformation behavior of the product as well as the fraction of austenite. ${ }^{[3]}$ From these studies, the understanding of bainite transformation has progressed significantly during the past three decades.

However, the knowledge obtained is not necessarily applicable to the industrial processes. The recent trend of industrial research is to focus on low-alloyed TRIP steels. The basic composition of low-alloyed TRIP steel is Fe-(1-2) Si-(1-2)Mn-(0.1-0.2) C in wt pct. ${ }^{[9]}$ The bainite transformation of this type of steel is relatively fast. Therefore, austempering typically takes less than 1000 seconds. This situation is somewhat different from the lower bainite transformation of high-carbon $(\sim 0.6$ wt pct) steels, reported by Rakha et al. ${ }^{[7]}$ Stone et al. ${ }^{[8]}$ and Nishijima et al. ${ }^{[6]}$ These studies reported inhomogeneous carbon enrichment in austenite during austempering, which was observed as the asymmetrical irregular shapes of diffraction peaks for austenite. It should be confirmed whether the relatively fast reaction 
in the low-carbon TRIP steel show similar behavior. Guo et al. found that during austempering, the untransformed austenite consisted of two different parts containing high ( $1.2 \mathrm{wt}$ pct) and low (0.2 to $0.4 \mathrm{wt}$ pct) amounts of carbon. ${ }^{[5]}$ They used Fe-0.91Si-1.37Mn$1.54 \mathrm{Cr}-0.1 \mathrm{Cu}-0.14 \mathrm{Mo}-0.06 \mathrm{Ni}-0.22 \mathrm{C}$. The higher value of the carbon concentration, $1.2 \mathrm{wt}$ pct, was almost on the $T_{0}$ line, where the Gibbs free energies for ferrite and austenite are the same. This appears somewhat contradict the idea suggested by Bhadeshia that the bainite transformation should stop at the $T_{0}{ }^{\prime}$ concentration, which is lower than $T_{0 .}{ }^{[1]}$ Therefore, the inhomogeneous distribution of carbon in austenite is the key obtaining an in-depth understanding of bainite transformation.

The in situ observation of the dynamic phenomenon requires fast and quantitative data acquisition. As for the in situ phase fraction determination, studies using high-energy transmission X-ray diffraction have most frequently been reported. ${ }^{[5-8]}$ Owning to the superior flux of synchrotron X-rays and the advanced analysis technique for the 2D images of Debye-Scherrer rings, the data acquisition time can be less than 1 minute. However, the disadvantage of this technique involves lack of the resolution in $q$ - or $d$-spacing $\left(\propto q^{-1}\right)$ due to the forward scattering nature, which may result in a qualitative and ambiguous analysis of the lattice parameter, i.e., carbon concentration.

In this study in situ observations of austempering for Fe-1.5Si-1.5Mn-0.15C (wt pct) were made by using Time-Of-Flight (TOF) type neutron diffraction. The properties could be quantitatively determined with a time resolution of 1 minute, which successfully captured the bainite transformation and accompanying carbon diffusion. The results obtained are reasonably consistent with the microstructures after the heat treatment. The inhomogeneous carbon enrichment occurs also in the current case. This resulted in a bimodal distribution of carbon concentration. It seems, however, that the highand low-carbon austenite parts do not necessarily correspond to the morphologies - film and block, respectively. The higher side of the carbon concentration observed in this study exceeded the concentration at the $T_{0}$ line.

\section{EXPERIMENTAL METHOD}

\section{A. Measurement and Analysis}

A strategy for the quantitative determination of phase fractions in steels using iMATERIA was previously proposed.$^{[10]}$ This was an application of Rietveld texture analysis (RTA) through multiple TOF neutron diffractograms in a wide range of scattering directions ${ }^{[11,12]}$ using the MAUD software. ${ }^{[13]}$ The notable advantage of this method was that the phase fraction could quantitatively be determined even if severe textures existed. The phase fraction is often determined by the comparison of integrated intensities of peaks for ferrite and austenite. ${ }^{[14]}$ However, a result of this simple method may be affected by textures, which is not suitable for industrial materials, such as having sheet forms. ${ }^{[10]}$ The details of the analysis can be found in previous work. ${ }^{[10,15]}$

RTA has also been applied in synchrotron X-ray diffraction. ${ }^{[5,16,17]}$ The strategy used here is distinguished from other methods by designating it as "neutron-diffraction-based Rietveld texture analysis" (NDRTA). The iMATERIA measurement for NDRTA does not require any rotation or movement of either the sample or the apparatus (the detector). Such a one-shot method is advantageous for the in situ observation of dynamically changing structures. Repeating the measurements (e.g., at different sample angles) for one integrated analysis may cause some difficulties in the integration of the results, because each measurement was carried out at a different time.

The lattice parameter was determined by the position of $111 \gamma$ diffraction peak in the diffractograms observed by the entire 90 deg bank (Banks 81, 90, and 99, see Reference 10) with a binning width of $2 \mu$ s for TOF. As described in the following sections, a peak splitting was observed for the austenite phase. Hence, it was necessary to distinguish the overlapped contributions. For this purpose, the Gaussian fitting of the single diffraction peak, $111 \gamma$, was applied. A similar analysis was attempted for synchrotron X-ray data by Guo et al. ${ }^{[5]}$ In their case, they used $200 \gamma$ because of the overlap of $111 \gamma$ and $110 \alpha$. This was because of the broad peak shape seen in the forward scattering experiment. Generally, the peak width (called instrumental broadening) becomes smaller with increasing $2 \theta$ and an arbitrary scattering angle can be chosen in case of TOF-type neutron diffraction. Then, the isolated $111 \gamma$, which provided the best resolution and integrated intensity, was available.

The in situ neutron experiments were conducted with a proton beam power of $300 \mathrm{~kW}$. Since the incident neutron flux was proportionally increased with the proton beam power, the time resolution reported in this paper will therefore be finer when the maximum beam power at J-PARC, $1000 \mathrm{~kW}$, is achieved.

Electron backscatter diffraction (EBSD) measurement was carried out for the samples after the in situ neutron diffraction experiment to investigate the microstructure using a Schottky field emission scanning electron microscope, SU5000 (Hitachi), equipped with AMETEK EDAX orientation imaging microscopy. The crosssection perpendicular to the transverse direction in the rolling process was measured. The sample surface was prepared by mechanical polishing and subsequent electrolytic polishing. A $0.16 \mathrm{~mm} \times 0.16 \mathrm{~mm}$ area was scanned, using a step size of $0.2 \mu \mathrm{m}$.

\section{B. Sample}

The composition of the tested sample was Fe-1.48Si$1.52 \mathrm{Mn}-0.15 \mathrm{C}$ in wt pct. The cast and hot-forged plate was hot-rolled to $6 \mathrm{~mm}$ in sheet thickness and slowly cooled in a furnace. After the surface was milled to remove the oxide layers, the sample was cold-rolled to a final thickness of $2.0 \mathrm{~mm}$.

Based on the chemical composition of the sample, transformation temperatures upon cooling were estimated in this study to assist in understanding how the 


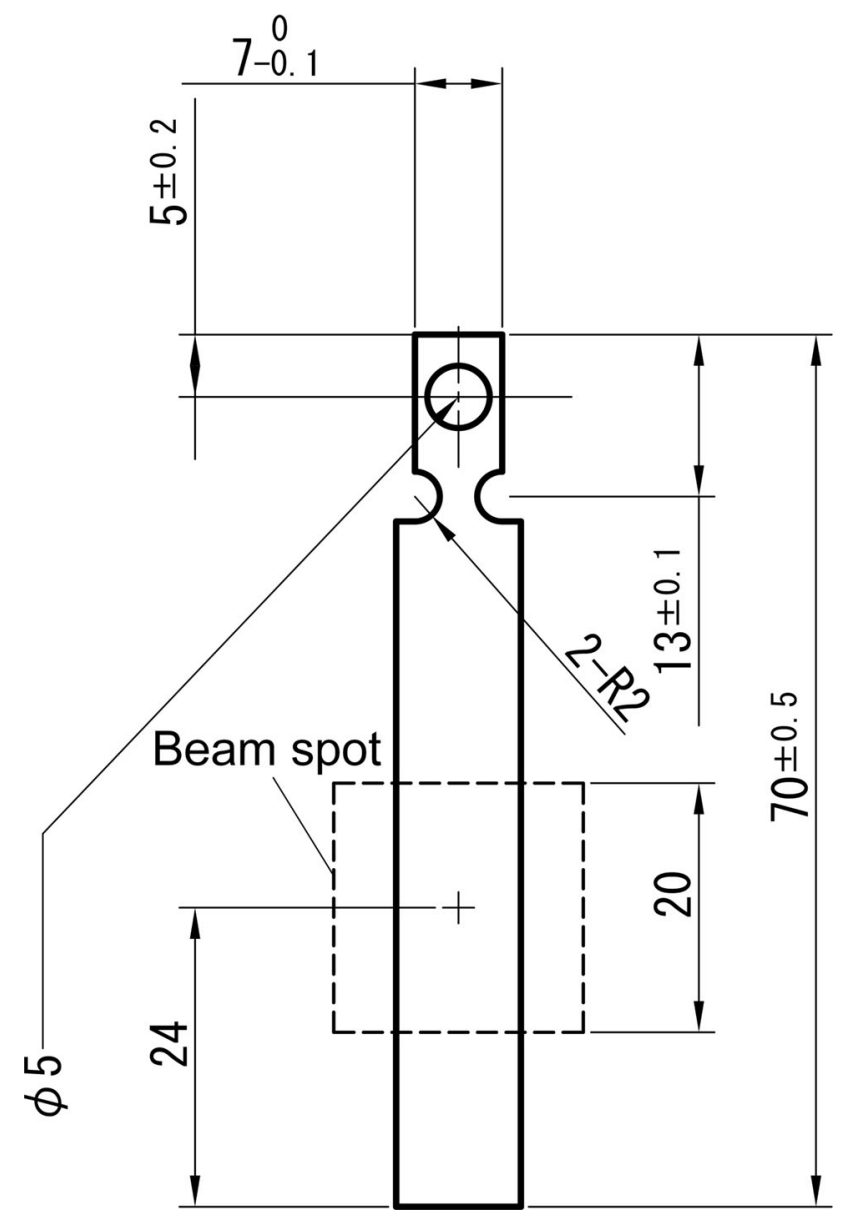

Fig. 1-Shape of test coupon and position of the incident beam spot. bainite transformation occurs in the austempering treatment. According to the equations put forward by Andrews, the transformation temperatures, $A_{\mathrm{c} 3}, A_{\mathrm{c} 1}$, and $M_{\mathrm{S}}$ are 1171,1023 , and $696 \mathrm{~K}$, respectively. ${ }^{[18]}$ The bainite start temperature, $B_{\mathrm{s}}$, was estimated to be $844 \mathrm{~K}$ by MAP STEEL MUCG83 software. ${ }^{[1,19]}$ This software also predicted $M_{\mathrm{S}}$ as $707 \mathrm{~K}$, which was fairly close to the estimation by the Andrews equation.

Heat treatment experiments are often conducted on steel using thin cylindrical samples for ease of temperature control (especially with the increase in cooling rate), as reported in the literature. ${ }^{[20]}$ However, in this study, the focus was on the observations for a "rolled and textured sheet" from a practical or industrial perspective, which was allowed by the large penetration depth of thermal neutrons into steel samples. The shape of the sample used in this study (Figure 1) was cut from the cold-rolled sheet by spark erosion. The hole on the top was used to attach the sample to the sample rod in Figure 2(a). The beam center was $24 \mathrm{~mm}$ away from the bottom edge (Figure 1) at room temperature.

\section{Heat Treatment Schemes}

To conduct the in situ neutron diffraction experiment, the quadruple-lamp infrared ray furnace shown in Figure 2 was developed. It was capable of rapid heating at more than $10 \mathrm{~K} / \mathrm{s}$. Quenching was performed by a helium gas jet at a cooling rate greater than $20 \mathrm{~K} / \mathrm{s}$. As shown in Figure 2(b), the beam paths were not obstructed by any part of the equipment. The details of the instrument will be introduced elsewhere in future.

Two different heating schemes were applied in this study. The sections consisting of heating and isothermal stasis were virtually identical in the two schemes; (Step

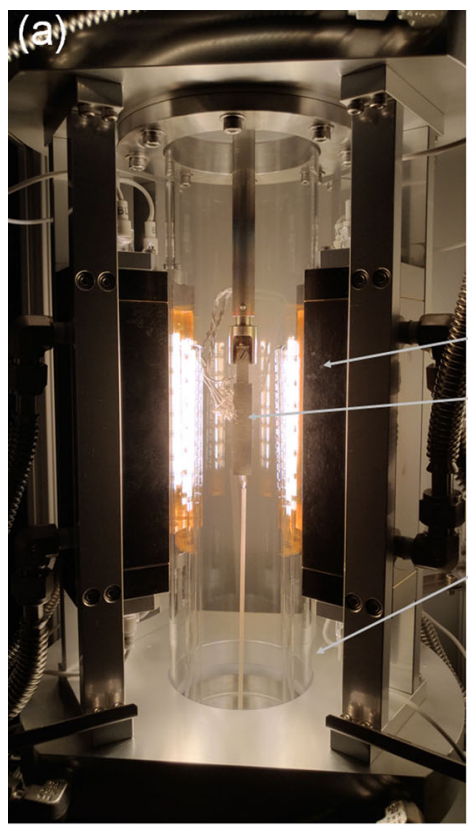

(b)

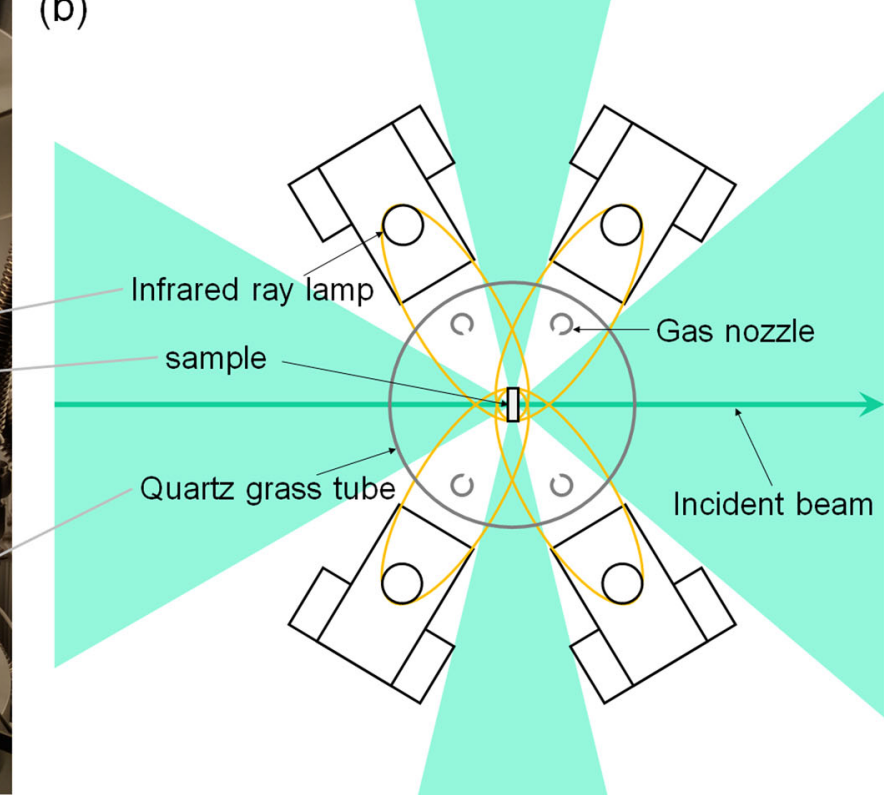

Fig. 2-The infrared ray furnace for the in situ observation of steel sample during heat treatment. (a) Photograph, (b) schematic of instrument positions. 


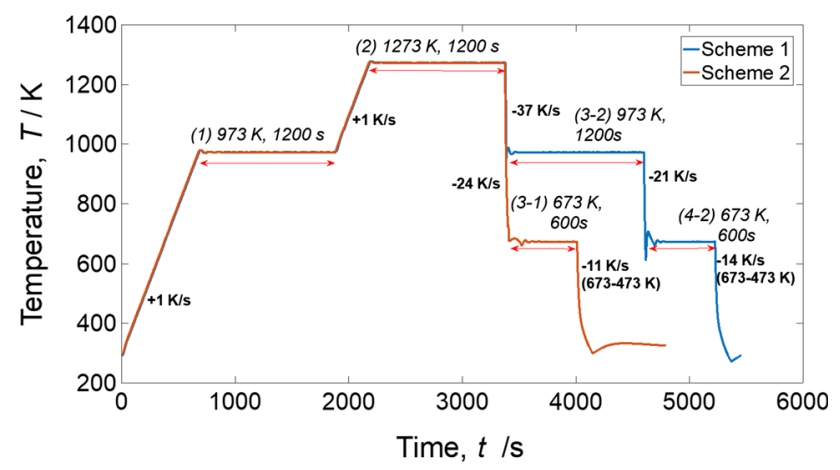

Fig. 3-Temperature histories applied in this study.

1) heating to $973 \mathrm{~K}$ at $1 \mathrm{~K} / \mathrm{s}$ and maintaining this temperature for 1200 seconds, and (Step 2) heating to $1273 \mathrm{~K}$ at $1 \mathrm{~K} / \mathrm{s}$ and maintaining the temperature for 1200 seconds. In Scheme 1, the sample was first quenched to $973 \mathrm{~K}$ (Step 3-1), then $673 \mathrm{~K}$ (Step 4-1), and finally to room temperature. In Scheme 2, quenching (Step 3-2) to $673 \mathrm{~K}$ and maintaining for 600 seconds immediately after Step 2, followed by quenching to ambient temperature $(303 \mathrm{~K})$. In the quenching sequences, the heating was interrupted and the helium gas flowed under a constant pressure to obtain the maximum cooling rate. The main difference between the schemes was the existence of Step 3-2, the soaking at $973 \mathrm{~K}$ after full austenization at $1273 \mathrm{~K}$ for Scheme 1 . Figure 3 indicates the measured heating curves for the two schemes.

\section{RESULTS}

\section{A. Average Phase Fractions and Textures}

The austenite phase fractions, $V \gamma$, determined by the NDRTA during the isothermal heating steps in Schemes 1 and 2 are listed in Tables I and II, respectively. Because every diffraction dataset used here covers the entire duration of each isothermal step, any change during the isothermal heating is averaged. The remaining part $(100-V \gamma)$ consists mainly of ferrite, but a cementite $\left(\mathrm{Fe}_{3} \mathrm{C}\right)$ phase is also observed in some steps. Although this phase was not included in the RTA because of its negligible diffraction intensity, cementite diffraction peaks were still detectable. Therefore, the presence of cementite is also listed in Tables I and II. The confirmation of phases present was accomplished based on the visibility of the corresponding diffraction peak. Therefore, the " $n$ " entries in Table I do not necessarily signify the complete absence of cementite, because of the uncertainty in the diffractograms.

The initial state consists of ferrite and cementite (pearlite). These two phases remain at Step 1. These are completely transformed to austenite at Step 2, which is commonly observed in both schemes. In Scheme 1, the cementite appears again at Step 3-1. As the value of $A_{\mathrm{c} 1}=1023 \mathrm{~K}$ is estimated by Andrews' equation, the precipitation of cementite is possible if there is sufficient diffusion of Si. At Step 4-1 in Scheme 1, the diffraction peaks of the austenite phase have irregular asymmetric shapes, as shown in Figure 4(a). This feature is not observed after cooling to room temperature as shown in Figure 4(b).

In Scheme 2, the presence of cementite is unconfirmed after austenizing. This is because of the retardation of cementite precipitation by $\mathrm{Si}^{[1]}$ As confirmed in Table II, $V \gamma$ is increased slightly by the cooling from $673 \mathrm{~K}$ to the ambient temperature. However, this difference is within the range of analytical error. The previous verification showed that the analyzed $V \gamma$ could have an analytical error of 5 pct. ${ }^{[10]}$ Rather, a more significant observation is the near-absence of the transformation of austenite in this cooling process.

Figure 5 shows the pole figure analyzed during Scheme 1. Although texture is not the key feature to be discussed here, it should be noted that textures exist for both ferrite and austenite in all the heating steps. In a comparison of Figures 5(a) and (h), similar pole distributions are observed, although the ferrite phase was completely transformed once in the heat treatment. This is known as the texture memory effect. ${ }^{[21]}$

\section{B. Carbon Concentration in Austenite}

The irregular peak shape of austenite during the austempering step in Scheme 1 can be expressed as the overlapping of two Gaussian profiles, as shown in Figure 6. This suggests that the austenite phase is separated into two states with different lattice

Table II. Austenite Fractions $(V \gamma)$ and Existence of Cementite at the Isothermal Heating Steps in Scheme 2

\begin{tabular}{llllll}
\hline Step \# & Initial & \multicolumn{1}{c}{1} & \multicolumn{1}{c}{2} & $3-2$ & After Cooling \\
\hline Temperature $(\mathrm{K})$ & 299 & 973 & 1273 & 673 & 303 \\
$V \gamma($ Vol Pct) & 0 & 0 & 100 & 6.0 & 6.4 \\
Cementite* & $\mathrm{p}$ & $\mathrm{p}$ & $\mathrm{n}$ & $\mathrm{n}$ & $\mathrm{n}$ \\
\hline
\end{tabular}

*p: positive (the peaks confirmed), n: negative.

Table I. Austenite Fractions $(V \gamma)$ and Existence of Cementite at the Isothermal Heating Steps in Scheme 1

\begin{tabular}{lllllll}
\hline Step \# & Initial & 1 & 2 & $3-1$ & 4-1 & After Cooling \\
\hline Temperature (K) & 299 & 973 & 1273 & 973 & 673 & 303 \\
$V \gamma$ (Vol Pct) & 0 & 0 & 100 & 23.2 & $9.7 *$ & 7.1 \\
Cementite & $\mathrm{p}$ & $\mathrm{p}$ & $\mathrm{n}$ & $\mathrm{p}$ & $\mathrm{p}$ & $\mathrm{p}$ \\
\hline
\end{tabular}

$p$ positive (the peaks confirmed), $n$ negative.

*Irregular peak shape is observed. 

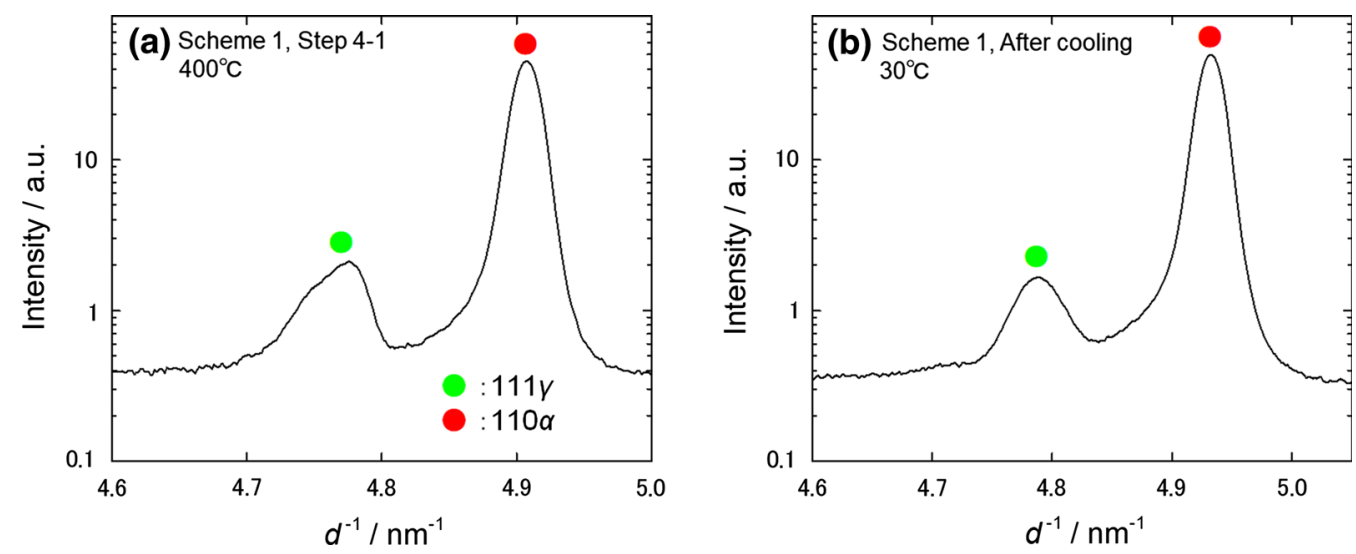

Fig. 4-Diffraction peaks observed by 90-degree banks at iMATERIA at $(a)$ step 4-1 (673 K) in Scheme 1 and $(b)$ after cooling to ambient temperature.

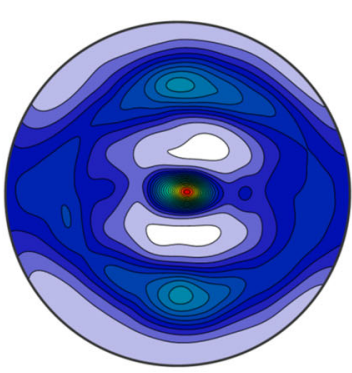

(a) Before heating $\{111\} \alpha$

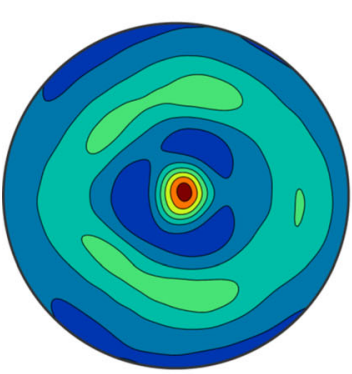

(d) Step 3-1 (973 K) $\{111\} \alpha$

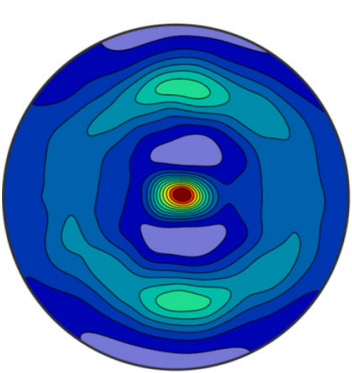

(h)After cooling $\{111\} \alpha$
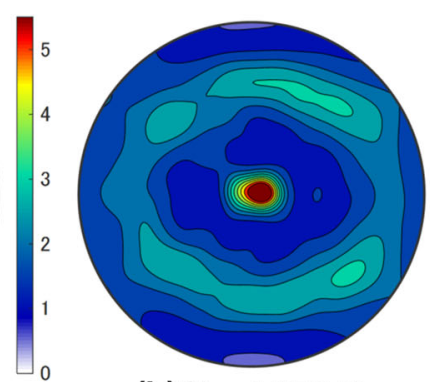

(b) Step 1(973 K) $\{111\} \alpha$
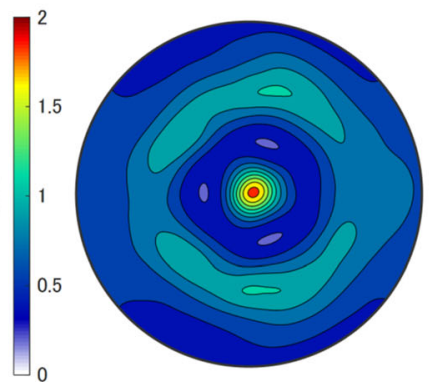

(e) Step 3-1 (973 K) $\{110\} y$
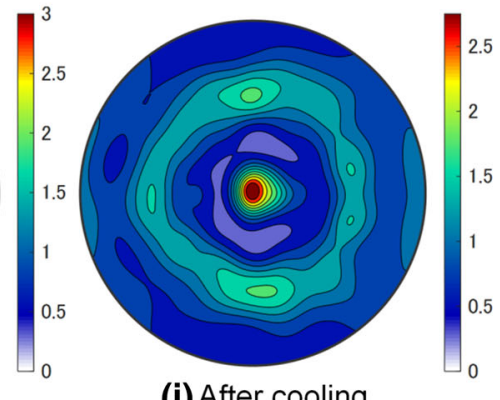

(i) After cooling $\{110\} y$

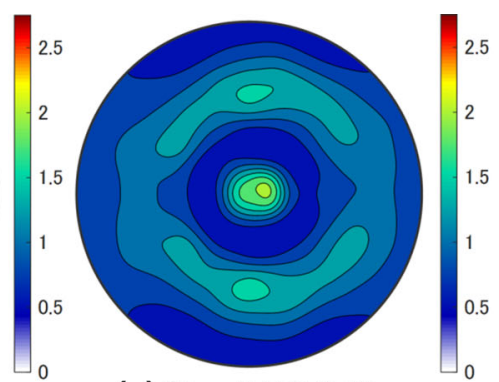

(c) Step 2 (1273 K) \{110\}Y
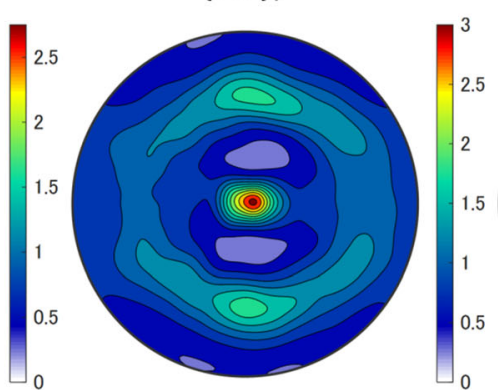

(f) Step 4-1 (673 K)

$\{111\} \alpha$

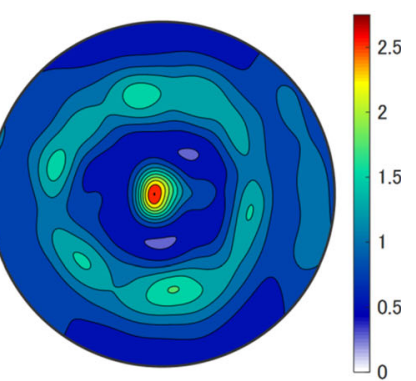

(g) Step 4-1 (673 K) $\{110\} \mathrm{Y}$

Fig. 5-Pole figures analyzed using integrated data at various heating steps in Scheme 1. $(a),(b),(d),(f)$, and $(h)$ are ferrite $(\alpha)$ and $(c),(e),(g)$, and $(i)$ are austenite $(\gamma)$. The contour increment step was 0.25 for all figures. 


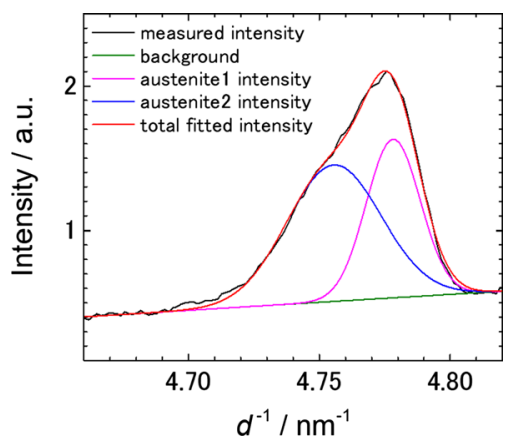

Fig. 6-Gaussian peak fitting for the $111 \gamma$ diffraction peak observed in step 4-1 $(673 \mathrm{~K})$ in Scheme 1.

parameters as reported by Guo et al. ${ }^{[5]}$ The lattice parameters corresponding to these peaks are $0.3625 \pm$ $0.0002 \mathrm{~nm}$ and $0.3642 \pm 0.0001 \mathrm{~nm}$.

According to previous literature, the addition of interstitial C linearly increases the lattice parameter. Addition of $\mathrm{Mn}$ also has a positive effect. Adding $\mathrm{Si}$ does not increase or decrease the lattice parameter. ${ }^{[22-24]}$ Dyson reported the relationship between the lattice parameter of austenite and various alloying elements. ${ }^{[22]}$ Although Dyson's equation has been frequently referred to in the studies of TRIP steels, the experimental data of Mn addition show a large discrepancy. Recent experimental studies using binary alloys by Onink et al. ${ }^{[24]}$ and Li et al. ${ }^{[25]}$ reported the effects of the presence of $\mathrm{C}$ and $\mathrm{Mn}$ on the lattice parameter, respectively. They also reported the effects of these elements on the thermal expansion coefficient, $\alpha_{\mathrm{A}}$. By combining their results, Lee et al. ${ }^{[23]}$ proposed and verified the following equation for $\mathrm{Fe}-\mathrm{C}-\mathrm{Mn}(-\mathrm{Si})$ alloys.

$$
\begin{gathered}
a_{\mathrm{A}}[\mathrm{nm}]=\left(0.35729+7.83 \times 10^{-4} X_{\mathrm{C}}+1.144\right. \\
\left.\times 10^{-4} X_{\mathrm{Mn}}\right)\left\{1+\alpha_{A}(T-298)\right\} \\
\alpha_{\mathrm{A}}\left[\mathrm{K}^{-1}\right]=\left(23.875-0.5 X_{\mathrm{C}}-0.1784 X_{\mathrm{Mn}}\right) \times 10^{-6},
\end{gathered}
$$

where $a_{\mathrm{A}}$ is the lattice parameter of austenite, $X_{\mathrm{C}}$ is the $\mathrm{C}$ concentration (at. pct), $X_{\mathrm{Mn}}$ is the $\mathrm{Mn}$ concentration (at. pct), and $\mathrm{T}$ is the absolute temperature $(\mathrm{K})$. Here, it is assumed that $X_{\mathrm{Mn}}$ is identical to that for the bulk composition, 1.51 at. pct. Although the segregation of $\mathrm{Mn}$ is often reported, $\mathrm{Mn}$ is soluble both in ferrite and austenite. Therefore, the deviation of $\mathrm{Mn}$ concentration in austenite from the bulk concentration seems to be small. Instead, the element most likely affecting the lattice parameter is C. The following equation is derived from Eqs. [1] and [2] when $T=673 \mathrm{~K}$ :

$$
a_{\mathrm{A}}=-1.468 \times 10^{-7} X_{\mathrm{C}}^{2}+7.229 \times 10^{-4} X_{\mathrm{C}}+0.36063 .
$$

Using the lattice parameters obtained from Figure 6, 0.3625 and $0.3642 \mathrm{~nm}$, the $\mathrm{C}$ concentrations are determined to be 0.58 and $1.12 \mathrm{wt}$ pct, respectively. Similar calculations are conducted for the austenite lattice
Table III. Carbon Concentrations $\left(X_{\mathrm{C}}\right)$ in the Austenite at Steps 3-1 and 4-1 and After the Final Cooling in Scheme 1

\begin{tabular}{lccc}
\hline Step \# & $3-1$ & $4-1$ & After Cooling \\
\hline $\begin{array}{l}\text { Temperature (K) } \\
X_{\mathrm{C}} \text { (Mass Pct) }\end{array}$ & 973 & 673 & 303 \\
$\begin{array}{l}\text { Low Carbon } \\
\text { High Carbon }\end{array}$ & 0.46 & 0.50 to 0.65 & \\
& & 0.81 to 1.20 & 1.25 \\
\hline
\end{tabular}

Table IV. Carbon Concentrations $\left(X_{\mathrm{C}}\right)$ in the Austenite at Step 3-2 and After the Final Cooling in Scheme 2

\begin{tabular}{llc}
\hline Step $\#$ & \multicolumn{1}{c}{$3-2$} & After Cooling \\
\hline Temperature (K) & 673 & 303 \\
$X_{\mathrm{C}}$ (Mass Pct) & & \\
Low Carbon & 0.18 & 1.20 \\
High Carbon & 1.13 to 1.32 & \\
\hline
\end{tabular}

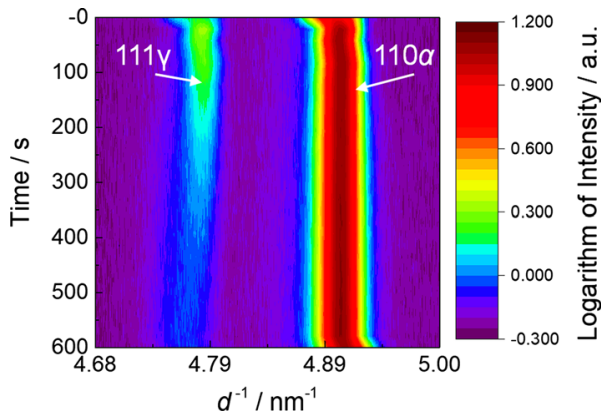

Fig. 7-Transitions of the diffractograms during austempering, step 4-1, in Scheme 1. Diffraction intensities are color-coded (Color figure online).

parameters after the full austenizing step. The results are summarized in Tables III and IV.

To observe the development of the bimodal distribution of carbon, a time-resolved analysis was attempted. The austempering scheme, the 4-1 step in Scheme 1, is resolved by 20 seconds. This reveals the transition of the diffractogram over time as shown in Figure 7, where the dynamic change of the $111 \gamma$ peak is observed whereas the $110 \alpha$ remains stable.

Figure 8 presents a summary of the changes in lattice parameters during austempering steps. The Gaussian fitting approach assuming the existence of two austenite phases is also applied here. As observed in Figure 8(a), a gradual increase of carbon concentration takes place, but a bimodal distribution is kept throughout the isothermal step in Scheme 1. However, the bimodal distribution of carbon immediately disappears in Scheme 2 as shown in Figure 8(b). The ranges in carbon concentrations shown in Tables III and IV correspond to the gradual increases of carbon concentration seen in this figure. 


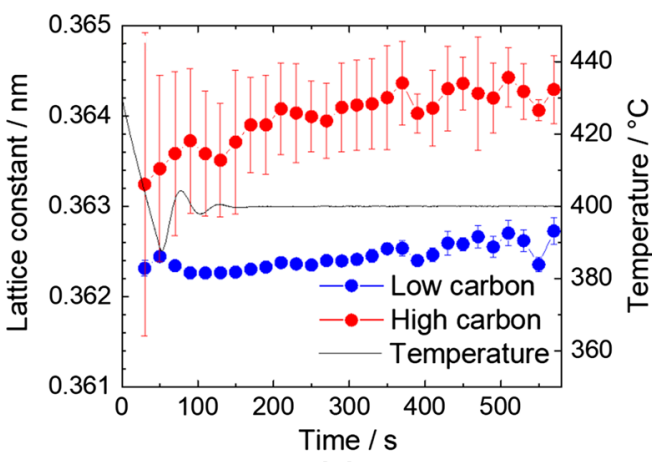

(a)

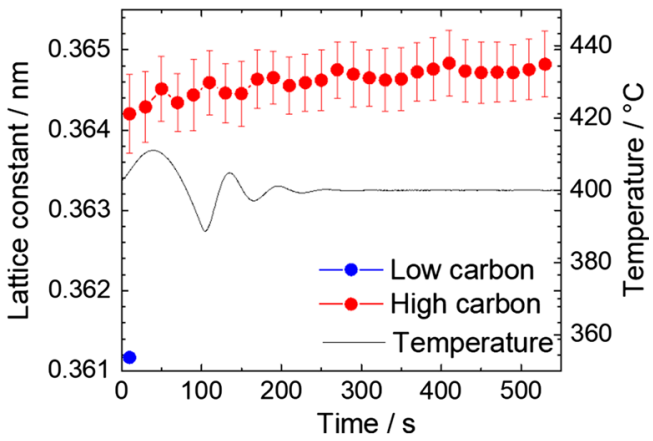

(b)

Fig. 8-Changes in the lattice parameters in 20-s intervals calculated by Gaussian peak fitting for $111 \gamma$ during $(a)$ step 4 - 1 in Scheme 1 and $(b)$ step 3-2 in Scheme 2. The time origin is set at the time when the cooling sequence is finished. Error bars show the standard deviation.

\section{Microstructure}

Figure 9 shows the EBSD measurement results for the samples used in the neutron diffraction study described above. The image quality (IQ) maps shown in Figures 9(a) and (b) indicate the clarity of the electron diffraction pattern at each measurement point, so that such defects as grain boundaries, as well as cell or lath boundaries, are identifiable as dark lines. As illustrated in Figure 9(a), the microstructure of the sample heated through Scheme 1 consists of granular ferrite and the colonies consisting of lath structure. On the other hand, the microstructure after Scheme 2 shown in Figure 9(b) is mostly covered with lath structures.

The phase maps, Figures 9(c) and (d), reveal the presence of block-shape austenite particles. The detected areal fractions of austenite for Schemes 1 and 2 are only 3 and 1 pct, respectively. They are much smaller than the quantity estimated by NDRTA. It has often been noted that the EBSD measurement tends to underestimate the fraction of the retained austenite. ${ }^{[14]}$ Although multiple explanations have been suggested, the most likely and simple reason is that the EBSD measurement may overlook fine or thin particles between the points of the pattern acquisition. Moreover, it does not account for indexing due to the overlapping pattern from multiple phases. ${ }^{[2]}$ As shown in Tables I and II, the retained austenite fractions after Schemes 1 and 2 do not differ significantly. Therefore, the significant difference in austenite fraction detected by EBSD results from the existence of the film-shaped austenite. The microstructure after Scheme 2 may contain greater fraction of thin film austenite than that after Scheme 1 because there should be more undetected austenite by EBSD.

\section{DISCUSSION}

\section{A. Dynamic Change and Bimodal Distribution of Carbon Concentration in Austenite During Austempering}

As confirmed in Figure 8, the consumable low-carbon austenite and stable high-carbon austenite are both present at the austempering stage. The former is consumed gradually by bainite transformation and the following martensite transformation during the final cooling, but the latter remains during the austempering. Most of the stable austenite remains even after cooling to ambient temperature.

The carbon concentrations after cooling show values similar to those of high-carbon austenite during austempering both in Schemes 1 and 2. Also, the carbon concentrations are almost identical after the final cooling; however, the microstructures after the two schemes shown in Figure 9 look quite different. Guo et al. explained that the high- and low-carbon austenite, respectively, correspond to the film- and block-shaped austenite grains. ${ }^{[5]}$ However, a considerable amount of block-shape austenite is observed after Scheme 1 in the current study. Hence, even block-shaped austenite can have a carbon concentration as high as 1.2 wt pct. Further studies are needed to clarify the relationship between morphology and carbon concentration. As discussed by Sugimoto et al., these factors are important for modifying the properties of TRIP steels. ${ }^{[27]}$

MAP_STEEL_MUCG83 software, was used to estimate the theoretical carbon concentrations at $673 \mathrm{~K}$ for the para-equilibrium state ( $X_{\text {eq }}$, value on the extended $A_{\mathrm{e} 3}$ line), on $T_{0}$ line $\left(X_{T_{0}}\right.$, where the free energies of $\alpha$ and $\gamma$ are identical), and $T_{0}^{\prime}$ calculated by assuming the strain energy of $400 \mathrm{~J} / \mathrm{mol}$ required by the shear transformation $\left(X_{T_{0}^{\prime}}\right)$. The results were; $X_{\mathrm{eq}}=1.51$ wt pet, $X_{T_{0}}=0.84$ wt pet, and $X_{T_{0}^{\prime}}=0.59$ wt pet. Although both the analysis and the estimation may contain certain errors, the analyzed carbon concentration for the high-carbon austenite is higher than $X_{T_{0}}$. Although further investigation with more data, e.g., microscopic observation, should be conducted, it is possible that the observed higher side of the carbon concentration is controlled by cementite precipitation. ${ }^{[28]}$

\section{B. Phase Fractions of High and Low-Carbon Austenite}

Figure 7 indicates the dynamic change of the austenite fraction during the isothermal heating, as well as the lattice parameters. The change of the phase fractions is analyzed by NDRTA every 60 seconds for Scheme 1. NDRTA usually refines many parameters simultaneously, including lattice constants, phase fractions, 
Scheme 1

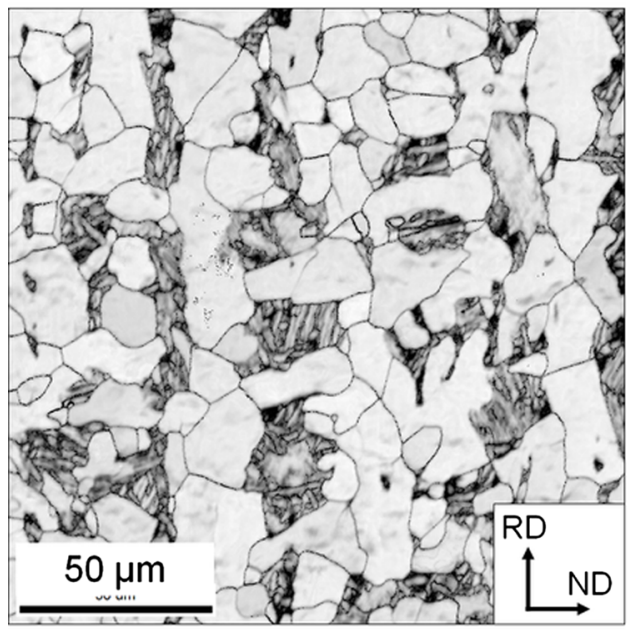

(a)

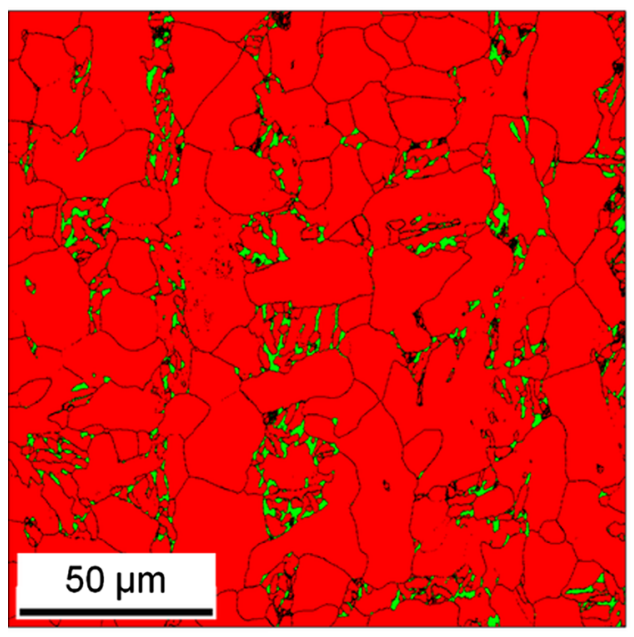

(c)
Scheme 2

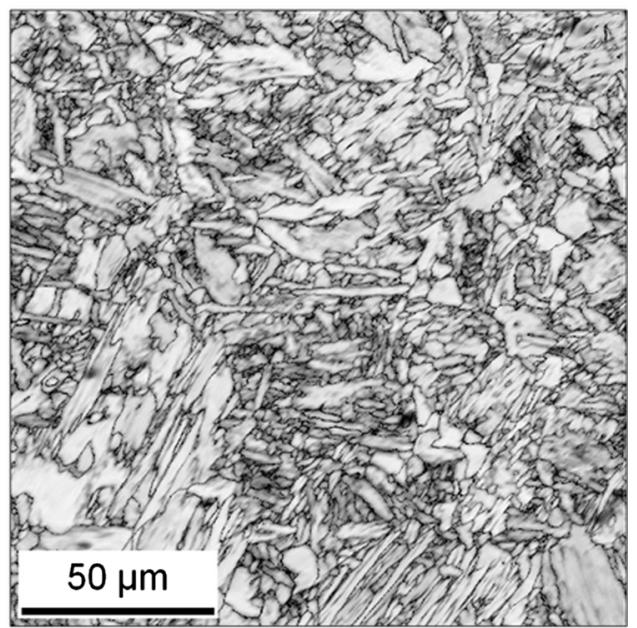

(b)

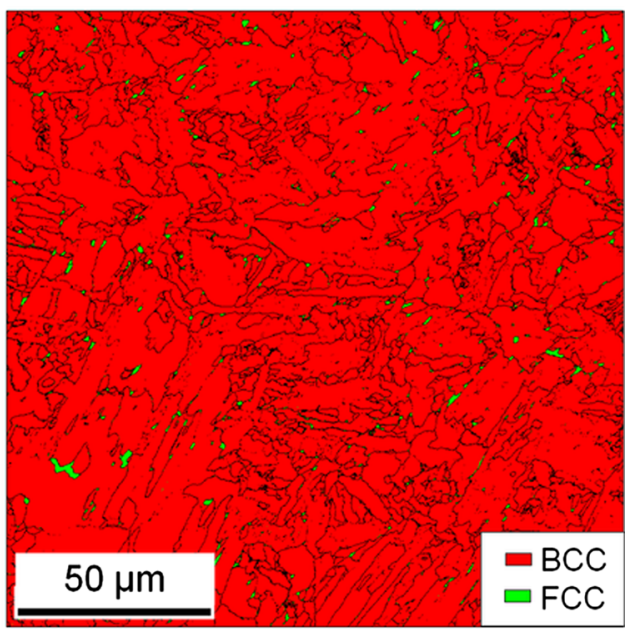

(d)

Fig. 9-Results of EBSD measurements for the samples heated by $(a, c)$ Scheme 1 and $(b, d)$ Scheme 2. (a, b) IQ (image quality) maps, and (c, d) phase maps (red: BCC, green: FCC). Points with confidence index below 0.1 are rejected, and black lines represent the high angle ( $>15$ deg) grain boundaries (Color figure online).

Debye-Waller factors $\left(B_{\text {iso }}\right)$, and textures. However, refining these many parameters with poor-quality data (i.e., data from insufficient exposure time) can lead to large uncertainties. Therefore, only volume fractions, peak shapes, and other essential parameters (scale factors and background) are refined. Because the textures and $B_{\text {iso }}$ factors seem to be almost independent during the isothermal heating, the results from the averaged data shown in the previous section are used. Two austenite phases, $\gamma_{1}$ and $\gamma_{2}$, are designated as the low- and high-carbon phases, respectively. The lattice parameters are fixed at the values obtained by the Gaussian fitting analysis shown in Figure 8(a).

The result is shown in Figure 10. The volume fraction of austenite during Step 3-1 (973 K) reaches the value shown in Table I, 23 pct, within several minutes. This confirms that the analyses using a time interval of 60 seconds are as reliable as the averaged data taken over 1200 seconds. The change of austenite fraction during Step 4-1 takes place more slowly, and the reduction of the total amount of austenite is mainly caused by the low-carbon austenite, $\gamma_{1}$. On the contrary, $\gamma_{2}$ increases slightly from 7.7 to 8.3 pct. The average of the total fraction of austenite during Step 4-1 is higher than the value listed in Table II, 9.7 pct. This could be because of the irregularly shaped austenite peaks being fitted by a single phase (i.e., a single lattice constant) resulting in a poor approximation.

The martensite start temperatures, $M_{\mathrm{S}}$ for $\mathrm{Fe}-1.48 \mathrm{Si}$ 1.51Mn-0.6C and Fe-1.48Si-1.51Mn-1.2C, are estimated to be 505 and $237 \mathrm{~K}$, respectively by using MAP_STEEL MUCG83 software. These indicate that the low-carbon austenite transforms into martensite in the final cooling step while the high-carbon austenite remains. In effect, the volume fraction of $\gamma_{2}$ is similar to that of the retained fraction. The dark regions 


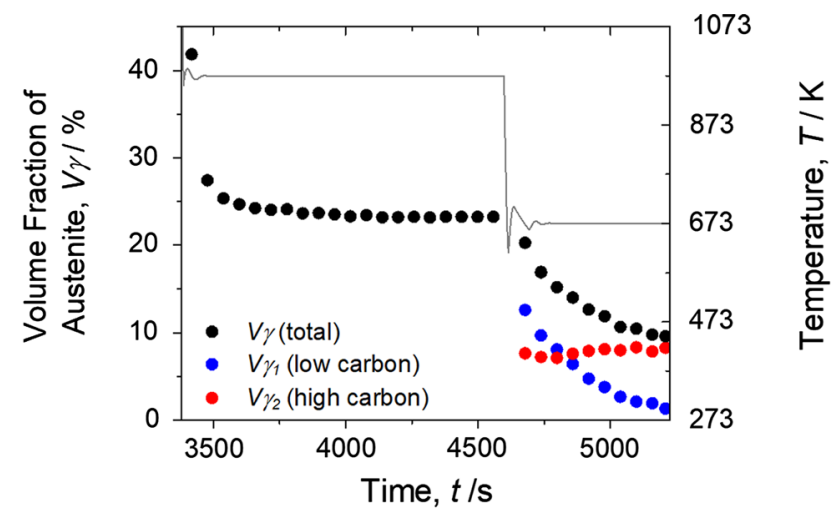

Fig. 10-Change of austenite volume fraction in 60-s intervals during steps $3-1(973 \mathrm{~K})$ and $4-1(673 \mathrm{~K})$ in Scheme 1. The time origin is set at the time when heating started. The standard deviations are smaller than the symbols used to represent the data. The solid line indicates temperature.

confirmed in Figures 9(a) and (c) may be the martensite that was the low-carbon austenite before the final cooling.

\section{Effect of Temperature History Prior to Austempering}

As explained above, the low-carbon austenite disappears at a very early stage of the austempering step in Scheme 2. Both the lattice constant and integrated intensity of the peak of the high-carbon austenite are very stable, so the dynamic volume fraction analysis by NDRTA is not attempted in this case. Because the estimated martensite starting temperature is approximately $700 \mathrm{~K}$ for the bulk composition, it may be possible that the fast transformation observed was martensite transformation. However, the transformation actually started during cooling from Step 2 to 3-2 and took approximately 60 seconds to achieve the steady state shown in Figure 8. Together with the microstructural similarity to the results from Scheme 1, it is concluded that the lath structure formed by Scheme 2 was also composed of upper bainite.

The notable difference of the transformation rate between Schemes 1 and 2 should be caused by the difference in the initial carbon concentrations of austenite at the beginning of the bainite transformation. In the case of the fast bainite transformation in Scheme 2, most of the retained austenite forms in a film shape between the ferrite laths. This is because of the lack of time necessary for the carbon to diffuse. In Scheme 1, where the bainite transformation proceeds more slowly, carbon can diffuse through the austenite, resulting in the blocky shape of the retained austenite. However, they do not immediately achieve uniform distribution. The bainite transformation preferentially takes place in the remaining low-carbon region.

In Scheme 2, the initial carbon concentration is identical to the bulk composition, 0.15 pct. In effect, the single point of the low-carbon austenite observed in Figure 8(b) corresponds to a carbon concentration of 0.18 pct. In Scheme 1, however, the first plot for the low-carbon austenite in Figure 8(a) corresponds to a carbon concentration of 0.50 pct, which is also similar to the carbon concentration achieved in the previous step. Therefore, it is considered that the low-carbon austenite phase, $\gamma_{1}$, is virtually identical to the austenite before cooling to the austempering temperature.

\section{CONCLUSIONS}

Attempts to observe the dynamic microstructural changes that occur during the heat treatment of $\mathrm{Fe}$ 1.48Si-1.52Mn-0.15C steel via TOF-type neutron diffraction were made. Two heating schemes were applied, with and without the isothermal heating at $973 \mathrm{~K}$ after full austenizing and before austempering at $673 \mathrm{~K}$. The main conclusions are summarized as follows.

1. Carbon concentrations in the austenite phase at various temperatures were estimated by the positions of 111 diffraction peaks. A bimodal distribution of carbon was confirmed during the austempering at $673 \mathrm{~K}$ after quenching from $973 \mathrm{~K}$. In the case of the austempering immediately after full austenizing, bainite transformation proceeded rapidly. The bimodal distribution was observed only in the first 20 seconds in the austempering step.

2. The phase fractions of high- and low-carbon austenite were determined by neutron-diffractionbased Rietveld texture analysis. While the lowcarbon austenite gradually decreased during austempering after $973 \mathrm{~K}$, the high-carbon austenite slightly increased.

3. The retained austenite found after the final cooling to room temperature had a close volume fraction and carbon concentration to those of high-carbon austenite at the end of austempering. The blockshaped retained austenite was detected by EBSD, but its fraction was much lower than that detected by neutron diffraction. There should be film-shaped austenite that neutron diffraction can account for but EBSD cannot.

4. Isothermal heating at $973 \mathrm{~K}$ resulted in a large fraction of block-shaped retained austenite. However, the average carbon concentrations in the final microstructures were almost identical regardless of the presence of heating at $973 \mathrm{~K}$. Hence, the block and film shapes do not necessarily correspond to the high and low-carbon austenite observed during austempering.

\section{ACKNOWLEDGMENTS}

This work was funded by the Ishihara/Asada Grant of the Iron and Steel Institute of Japan. This work was also partially supported by the Research Society for Quantum-beam Analysis of Microstructures and Properties of Steels. The neutron experiment at the Materials and Life Science Experimental Facility of J-PARC was performed as per the proposal 2017PM0003. 


\section{REFERENCES}

1. H.K.D.H. Bhadeshia: Bainite in Steels, 3rd ed., Many Publishing, Leeds, UK, 2015.

2. O.D. Sherby, J. Wadsworth, D.R. Lesuer, and C.K. Syn: Mater. Trans., 2008, vol. 49, pp. 2016-27.

3. Y. Tomita and T. Okawa: Mater. Sci. Technol., 2013, vol. 11, pp. $245-51$.

4. S. Zaefferer, J. Ohlert, and W. Bleck: Acta Mater., 2004, vol. 52 , pp. $2765-78$.

5. L. Guo, H.K.D.H. Bhadeshia, H. Roelofs, and M.I. Lembke: Mater. Sci. Technol., 2017, vol. 33, pp. 2147-56.

6. H. Nishijima, Y. Tomota, Y. Su, W. Gong, and J.-I. Suzuki: Metals, 2016, vol. 6, p. 16.

7. K. Rakha, H. Beladi, I. Timokhina, X. Xiong, S. Kabra K.-D. Liss, and P. Hodgson: Mater. Sci. Eng. A, 2014, vol. 589, pp. 303-09.

8. H. Stone, M. Peet, H. Bhadeshia, P. Withers, S.S. Babu, and E.D. Specht: Proc. R. Soc. Lond. A, 2008, vol. 464, pp. 1009-27.

9. M.Y. Sherif, C.G. Mateo, T. Sourmail, and H.K.D.H. Bhadeshia: Mater. Sci. Technol., 2004, vol. 20, pp. 319-22.

10. Y. Onuki, A. Hoshikawa, S. Sato, T. Ishigaki, and T. Tomida: $J$. Mater. Sci., 2017, vol. 52, pp. 11643-58.

11. H.R. Wenk, L. Lutterotti, and S. Vogel: Nucl. Instrum. Methods Phys. Res. A, 2003, vol. 515, pp. 575-88.

12. H.R. Wenk, S. Matthies, and L. Lutterotti: Mater. Sci. Forum, 1994, vols. 157-162, pp. 473-80.

13. L. Lutterotti, S. Matthies, H.R. Wenk, A.S. Schultz, and J.W. Richardson: J. Appl. Phys., 1997, vol. 81, pp. 594-600.

14. P.J. Jacques, S. Allain, O. Bouaziz, A. De, A.F. Gourgues, B.M. Hance, Y. Houbaert, J. Huang, A. Iza-Mendia, S.E. Kruger, M. Radu, L. Samek, J. Speer, L. Zhao, and S. van der Zwaag: Mater. Sci. Technol., 2009, vol. 25, pp. 567-74.
15. Y. Onuki, A. Hoshikawa, S. Sato, P. Xu, T. Ishigaki, Y. Saito, H. Todoroki, and M. Hayashi: J. Appl. Crystallogr., 2016, vol. 49, pp. 1579-84.

16. R. Blondé, E. Jimenez-Melero, L. Zhao, J.P. Wright, E. Brück, S. van der Zwaag, and N.H. van Dijk: Acta Mater., 2012, vol. 60, pp. 565-77.

17. L. Lutterotti, D. Chateigner, S. Ferrari, and J. Ricote: Thin Solid Films, 2004, vol. 450, pp. 34-41.

18. K.W. Andrews: J. Iron Steel Inst., 1965, vol. 203, pp. 721-27.

19. H.K.D.H. Bhadeshia: Met. Sci., 2013, vol. 16, pp. 159-66.

20. T. Suzuki, Y. Ono, G. Miyamoto, and T. Furuhara: ISIJ Int., 2010, vol. 50, pp. $1476-82$.

21. T. Tomida: Acta Mater., 2018, vol. 146, pp. 25-41.

22. D. Dyson and B. Holmes: J. Iron Steel Inst., 1970, vol. 208, pp. 469-74.

23. S.-J. Lee, S. Lee, and B.C. De Cooman: Scr. Mater., 2011, vol. 64, pp. 649-52

24. M. Onink, C.M. Brakman, F.D. Ticherlarr, E.J. Mittermeijer, S. van der Zwaag, J.H. Root, and N.B. Konyer: Scr. Metall. Mater., 1993, vol. 29, pp. 1011-16.

25. C.-M. Li, F. Sommer, and E.J. Mittemeijer: Mater. Sci. Eng. A, 2002, vol. 325 , pp. $307-19$.

26. Y. Onuki, S. Sato, M. Nakagawa, K. Yamanaka, M. Mori, A. Hoshikawa, T. Ishigaki, and A. Chiba: Quantum. Beam. Sci., 2018, vol. 2, p. 11 .

27. K. Sugimoto, M. Misu, M. Kobayashi, and H. Shirasawa: ISIJ Int., 1993, vol. 33, pp. 775-82.

28. A. Zarei-Hanzaki, P.D. Hodgeson, and S. Yue: ISIJ Int., 1995, vol. 35 , pp. $79-85$

Publisher's Note Springer Nature remains neutral with regard to jurisdictional claims in published maps and institutional affiliations. 